\title{
BUILDING COALITIONS: Communication in Coalitions
}

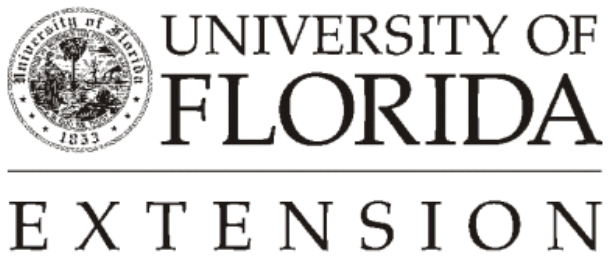

Institute of $\mathbf{F}_{\text {ood and }} \mathbf{A}_{\text {gricultural }} \mathbf{S}_{\text {ciences }}$ 


\section{What is It? How Do We Do It?}

Communication skills are important to developing professional and personal relationships. Relationships begin and grow through communication, and the quality of communication influences the quality of relationships. Effective communication skills are essential. Without them, one's effectiveness in all roles in life--professional, leader, manager, parent friend, etc.-- is limited.

Coalitions have been defined as "individuals or organizations working together in a common effort...for a common purpose to provide better services at lower cost." Good communication is required for individuals or individual organizations to establish coalitions, cooperate with one another, determine a common purpose and coordinate efforts. The first step in developing these skills is to understand what communication is, ways we communicate and methods of communication. This is particularly important when working with groups.

\section{What is Effective Communication?}

Communication is what we do to give and get understanding. It is an exchange of words and meanings, a two-way process of sending and receiving messages. Effective communication occurs when there is a shared meaning. The message that is sent is the same message that is received. There must be a mutual understanding between the sender and the receiver for the transmission of ideas or information to be successful.

For members of groups, effective communication may be defined as:

- Using language that is appropriate to others' levels of understanding.

- Making sure others receive the information or knowledge intended.

- Developing relationships with others.

- Talking with others in a way that facilitates openness, honesty and cooperation.

- $\quad$ Providing feedback.

\section{The Communication Process}

Effective communication is usually two-way. The two-way communication process includes:

A Sender--This is the first person to speak or the one who initiates the communication. 
A Receiver--This is the "listener," the one or ones for whom the message is intended. Receivers are usually interpreting and transmitting messages simultaneously. They are listening to what is being said and thinking about what they are going to say when the sender stops talking. Simultaneously, they may be reacting in nonverbal ways--with a smile or nod, flushed face, trembling hands or in some other way, depending on how they are interpreting the message.

The Message-- This is what the sender wants the receiver to know. It includes the verbal message (content) and nonverbal messages inferred from the sender and the environment.

Feedback--This is the lifeline of effective communication, the ingredient that distinguishes two-way from one-way communication. Without it, senders and receivers are far less likely to achieve mutual understanding about the message.

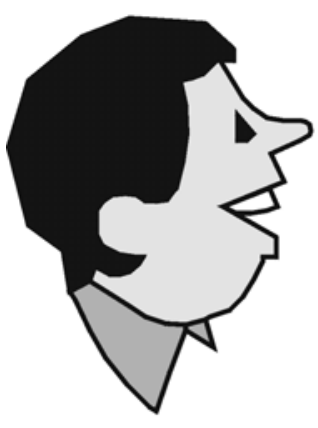

The Communication Process

\section{Message and Means of Communication

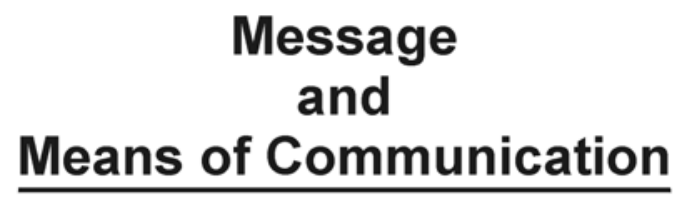

- telephone

- letter

- person-to-person

- ?

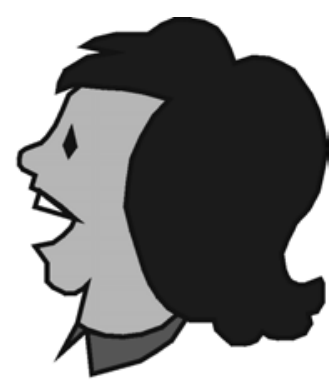

Sender

Purpose/Objective

Medium: should fit message

Encode: put into words

Transmit

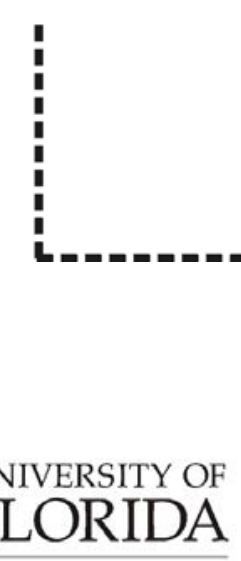

E X T E N S I O N

Institute of $\mathbf{F}_{\text {ood and }} \mathbf{A}_{\text {gricultural }} \mathbf{S}_{\text {ciences }}$
Building Coalitions

Part 5, Handout 5-B

FY497-P5, H5-B

\section{Receiver}

Reception

Decode: message interpreted

Meaning is assigned

Behavior (verbal or nonverbal)

\section{Feedback}

- to gain mutual understanding

- the lifeline of successful communication

.


After the first few seconds, interpersonal communication becomes a simultaneous two-way sending and receiving process. While senders are talking, they are receiving nonverbal reactions from receivers. Senders make inferences based on the receivers' reactions and adjust subsequent communication accordingly. For example, they may change their tone, speak loudly or use simpler language. The ability to do this results in the message being better understood. It helps prevent miscommunication.

\section{Miscommunication: A Breakdown in the Process}

Sometimes a breakdown occurs in the communication process. The message that was sent is not the message that was received. This can be due to a number of factors that act as barriers to or interfere with effective communication. Some things that can affect the interpretation of messages are:

- The environment. This includes room size, shape, lighting and color, temperature and furniture arrangement. These factors can either facilitate or interfere with the communication process. For example, a small conference room is a more appropriate meeting place for a group of six to eight people than a large auditorium. Also, if the temperature is too cold or too hot, participants may be distracted and unable to focus on what is being done.

- $\quad$ The unique personal attributes of the sender and the receiver. These include things like appearance, educational backgrounds and the physiological state of each communicator at the moment. For example, we tend to listen more closely to someone whose appearance is clean and neat and who is educated, especially in professional settings. Also, a person who is calm is better able to receive the intended message than someone who is agitated or angry.

- Culture and psychological interference. Culturally, people are different with different interpretations of the same phenomena. Experiences in other cultures can lead to psychological interference in communication, that is, bias, prejudice and being close-minded. These attitudes may arise from the region of the country a person grows up in; an ethnic, racial or religious identity; a socioeconomic identity.

- $\quad$ The human tendency to perceive information selectively. People often hear what they want to hear, especially if it reaffirms established beliefs and values or supports personal decisions. This is sometimes a problem in groups because some individuals are intolerant of others who interpret the information differently. Although many people feel they are open-minded, unprejudiced and able to see all sides of an issue, there is a tendency to maintain an expected view of reality and miss the objective truth. We select what we want to hear.

- Substitution, addition and simplification. These things occur as messages are passed from person to person. Each receiver tends to alter the message unconsciously when he or she becomes the sender and passes it on to another. Members in a group can be told the same message at the same time; but, they will each "hear" it somewhat differently and, therefore, communicate it differently outside the group. 
These factors can lead to a breakdown in the communication process, especially in groups where there is a greater likelihood that one or more of these factors will be present. When a breakdown occurs, the result is miscommunication. The receiver gets a different message than the one intended. The results are usually negative and can include:

- $\quad$ Lost time

- $\quad$ Feelings of resentment

- $\quad$ Rumors

- $\quad$ Poor relationships

Because these results can greatly affect the cohesiveness of a group, it is critical that all members be aware of them and help safeguard against them.

\section{What Are the Ways We Communicate?}

There are at least three important ways we communicate. One way--symbolic communication--we do not often consciously think about, though it has an impact on the ways we react to and behave toward others. The other two ways--verbal and nonverbal communication--are generally better understood.

Symbolic Communication. Symbols can be defined as things that stand for or represent other things or objects that represent something abstract. The interpretation of the Greek work for it is "tokens, pledges, or signs by which one infers a thing." Symbols play an important role in our interactions. They are often the basis for many of our reactions to other people and their consequent behaviors.

The symbols in our lives include where we work, our job titles, where we live, the vehicles we drive, the clothes and jewelry we wear, etc. It also includes more personal characteristics like age, gender, educational level, ethnic background and cultural heritage. We constantly process this information and "size people up," whether it is those we see on the street or those with whom we interact frequently. We often make judgements about people based on this symbolic information. The problem with this is that these assumptions are frequently wrong.

Think about attending the first meeting of a community coalition. You do not know the facilitator, who comes in wearing old, worn clothes and is slightly unkempt. He is also loud and boisterous and fails to get the meeting started on time. What is your reaction? Probably not very positive. He lost credibility based on his appearance and behavior before you had the opportunity to meet him. If he had been well-dressed and well-mannered, your reaction would have been very different. Our behaviors toward people are often based on our observations with no real knowledge of whom the person is or anything about him or her. 
Verbal Communication. Verbal communication is carried out through symbols known as "words." It includes the actual words used to send messages and the way in which they are arranged into thought units. Because words are the primary symbols used in this type of communication, it includes both oral and written communications. Personal conversations, group discussions and speeches, as well as letters and memos, are all forms of verbal communication. Some are spoken and some are written.

Nonverbal Communication. Nonverbal communication is the most influential form. If the verbal and nonverbal messages being sent are not in agreement, receivers generally will believe what they "hear" nonverbally. If interpersonal communication is to be effective, people need to send verbal and nonverbal messages that are congruent with one another. For example, if an individual says, "I am not angry!" but has a flushed face, clenched teeth and fists, and speaks in an angry tone of voice, the message that is heard is, "I am very angry!"

There are four major categories of nonverbal communication:

1. Eye Contact--Effective eye contact includes spontaneous glances or looking or gazing at another person in a way that communicates concern, interest, support and so forth. Appropriate eye contact is an excellent way to let others know we are interested in them and what they have to say. It says we respect them enough to listen and that we are open to communicating with them. On the other hand, ineffective eye contact tells others we are not interested in what they have to say or that we do not respect them. This includes staring, glaring, or not looking at another individual. For effective eye contact in groups, let your gaze move back and forth across the group. Look at everyone, or at least at every area of the room. Don't stare off into space or always look at one person or one side of the room.

2. Body Orientation--This refers to posture, body movements, facial expressions, limb placement, and so forth; Leaning toward and directly facing the sender of a message communicates interest and attention. If the receiver also has a relaxed face with a pleasant expression, a supportive communication climate is established. The communication process is hindered if the person is physically distant from or not facing the sender, does not use gestures, has no facial expression and is either slouching or having a rigid posture.

3. Verbal quality--That's right, verbal quality is a form of nonverbal communication. If verbal quality is to contribute to effective communication, the tone of voice must match the message. It is important that the person talking speak in an audible tone of voice that communicates confidence, strength, and directness. If the tone does not match the message, or the speaker appears to be passive and hesitant or demanding and authoritative, the listener will stop paying attention. The same is true if the sender frequently stutters, pauses, repeats things or uses incomplete, sentences. Who pays attention to the person who stutters, stammers, repeats things and mumbles? Who listens when the speaker is confident about what is being said and speaks audibly? 
4. Energy Level--Energy level is how we let others know we are interested in and enthusiastic about what we are doing, or that we could not care less. A person who is alert, bright, and receptive helps create an effective communication environment. If a person is apathetic, sleepy or jumpy, there probably will be breakdowns in the communication process. Energy level is contagious in groups. One enthusiastic person can turn a meeting with a group of tired, listless members into a lively encounter where a lot is accomplished. One apathetic, tired, person also can kill the group's enthusiasm.

\section{Effective Communication}

People today have more choices of communication methods than ever before. There are...

- $\quad$ Face-to-face conversations

- Meetings

- Telephones in offices, cars and airplanes

- $\quad$ Memos, letters, and telegraphs

- $\quad$ Electronic mail and F AX messages

- $\quad$ Media methods (such as newspapers, magazines, radio, television)

With so many choices, it is sometimes difficult to know how best to communicate. Keep three things in mind when selecting a method:

1. The importance of the message.

2. The effectiveness of different methods.

3. The kind of feedback you want.

If the message is important, it is often best to put it in writing. This is especially true if it is to be sent to several people or there is a need to document that information was shared. If it is an "oh, by the way..." type of message intended for one or two people, a phone call or note may do.

Different methods are more effective in some situations that others. For example, if there is no rush in sharing information with group members, distribute a memo at a meeting or put it in the mail. If there is more urgency, it may be appropriate to send it via electronic mail or fax. Keep in mind most people do not have ready access to a FAX machine. It may take more time to get the message from the machine to a person. 
It is sometimes wise to use a variety of communication methods to send the same message. A good example of this is when an important topic is to be discussed in a meeting. Providing a handout with pertinent information, outlining major points on a chalk board or flipchart and discussing the issue facilitates the process.

Remember that feedback is the lifeline of effective communication. It is easy to get in two-way, face-to-face communication. The receiver's reactions to the message (such as, agreement, surprise, boredom, hostility) can tell the sender a great deal. It allows one to get immediate indications of how the message is being received. In this situation, the individual involved can discuss the message, ask questions for clarification and resolve any misunderstandings. This is far more difficult when using written communication. Writers cannot clarify for readers because they do not see them. It is especially important to consider these factors when selecting methods to communicate with a group. Remember, you are working with busy people. They have many roles and responsibilities as well as hectic schedules. Use their time wisely!

\section{Summary}

Effective communication is a skill. It can be learned and improved upon with practice. This is necessary if individuals are to come together and become a group. Through the process of communication--sending and receiving messages--individuals can develop understanding and respect for one another, share information, challenge each other to think differently and find the best possible solutions to the issues around which the group has formed. 


\section{References}

Holli, B.B. and R.J. Calabrese. Communication and Education Skills, 2nd ed. Philadelphia: Lee and Febiger, 1991.

Hunt, G.T. Communication Skill in the Organization. Englewood Cliffs, N.J.: Prentice-Hall, 1980.

McNeese, I.C. Communication: Listening and Feedback. Family Community Leadership Program. Columbus: The Ohio State University Cooperative Extension Service, 1991.

McNeese, I.C. Communication: Model and Types. Family Community Leadership Program. Columbus: The Ohio State University Cooperative Extension Service. 1991.

\section{Authors}

Kathryn Beckham, Assistant Professor, Family Life Specialist, Ohio Cooperative Extension Service, The Ohio State University.

Jeffrey King, Assistant Professor/ Assistant Staff Development Specialist, Ohio Cooperative Extension Service, The Ohio State University.

(C) 1992 The Ohio State University

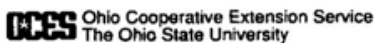

This series on Coalition Building was developed by The Ohio Center For Action on Coalition Development for Family and High Risk Youth, Richard Clark, Ph.D., Director. It has been adapted for County Extension Faculty in Florida to facilitate work with local and regional organizations and groups such as non-profits, cooperatives, county extension associations, and others that might benefit from a plan for working together to achieve support for mutual goals.

This document is FY497, Part 5 of the 16 part series adapted for use in Florida by Elizabeth B. Bolton, Professor, Community Development and Lisa Guion, Assistant Professor, Program Planning and Evaluation; Department of Family, Youth and Community Sciences, Florida Cooperative Extension Service, Institute of Food and Agricultural Sciences, University of Florida, Gainesville, 32611-0310.

Reprinted with permission March, 1997. Revised April, 2002.

The Institute of Food and Agricultural Sciences is an equal opportunity/affirmative action employer authorized to provide research, educational information and other services only to individuals and institutions that function without regard to race, color, sex, age, handicap, or national origin. For information on obtaining other extension publications, contact your county Cooperative Extension Service office.

Florida Cooperative Extension Service/Institute of Food and Agricultural Sciences/University of Florida/Christine Taylor Waddill, Dean 